\title{
Reflexões em um Campo de Fronteiras: Educação e Comunicação em Diálogo
}

\author{
Ricardo Cocco \\ Universidade Federal de Santa Maria - ricardo.cocco@ufsm.br
}

\begin{abstract}
Sumário
Os media representam nas sociedades contemporâneas não somente fontes de informação, mas constituem-se como mediadores, pelos quais o homem e a sociedade, em grande medida, vêm se relacionando, compreendendo e significando o mundo que os cerca. Mesmo não tendo o monopólio da informação, convivem e coexistem com outras instâncias também educativas e, juntamente com a escola, compõem um rol de meios através e com os quais os indivíduos dão inteligibilidade ao que o rodeia. Com o artigo, de bases teóricas e de caráter bibliográfico, pretendemos apontar elementos que nos parecem essenciais para pensarmos as múltiplas e complexas relações

entre a educação e os media. O que nos aparenta primordial ser discutido é que os media, tanto quanto as práticas pedagógicas institucionalizadas (escola), à sua maneira, podem ser compreendidos à luz das interações verbais, da sua faceta pedagógica e da produção de sentidos que neles e através deles ocorrem. É pela mediação da escola e dos media que o mundo que conhecemos é traduzido e significado. Advogamos que, em face aos vários cenários possíveis, sejam eles nos espaços escolares ou mediáticos, o diálogo vivo possibilita a constituição de uma individualidade permanentemente revisitada, infindavelmente revisada e criticamente refletida.
\end{abstract}

Palavras-chave: Educação, media, produção de sentido, diálogo formativo.

\section{Reflections in a Field of Borders: Education and Communication in Dialogue}

\begin{abstract}
The media represents, in contemporary societies, not only a source of information, but it's a mediator by which man and society have maintained high relations, understanding and meaning the world that surrounds them. Although they don't have the monopoly of information, they live and coexist with other educational instances and, along with school,

they compose a set of means with which people give intelligibility to their context. In this article, that has theoretical bases and a bibliographic character, we intend to show elements that are essential to think about the multiple and complex relations between education and media. Therefore, it's important to discuss that media, as well as the institutionalized
\end{abstract}


pedagogical practices (school), in its way, can be understood through verbal interactions, its pedagogical aspect and the production of meanings that happen in it. With the mediation of school and media, the world we know is translated and gets a meaning. So, in several possible situations, in media or school spaces, the living dialogue enables the constitution of an individuality that is permanently revisited, infinitely revised and critically reflected.

Keywords: Education, media, production of meaning, formative dialogue.

\section{PRESSUPOSTOS PARA A INVESTIGAÇÃO DE UM CAMPO DE FRONTEIRA: ENTORNO DA EDUCAÇÃO E COMUNICAÇÃO}

Os Meios de Comunicação Social e Informação (os media) representam não somente fontes de informação, mas constituem-se como mediadores, pelos quais o homem e a sociedade, em grande medida, vêm se relacionando, compreendendo e significando o mundo que os cerca. Eles são elementos muito presentes no processo de difusão de informações e hábitos, elaboração e apreensão de novas ideias, produção de sentidos, troca de conteúdos e mensagens, ao mesmo tempo que atuam fomentando espaços de socialização, relacionamento, interação e atuando no papel de agentes sociais de educação. Constituem espaços, nesta perspetiva, de aprendizagem não-formal na medida em que são agentes de produção de um número imensamente significativo de informações, valores, símbolos e significados que co-participam junto aos indivíduos na organização de suas vidas e suas ideias, a formarem suas opiniões ou oferecendo ferramentas para compreender, se adaptar ou transformar o seu mundo.

Enfim, os media, ou todo o aparato simbólico e material que se dedica deliberadamente à produção de mercadorias de caráter cultural, difundidas como instâncias de transmissão de valores, padrões, normas e significados agem na formação identitária e cognitiva dos indivíduos na atualidade. Mesmo não tendo o monopólio da informação, convivem e coexistem com outras instâncias educativas e neste sentido, juntamente com a escola, compõem de um rol de meios através e com os quais os indivíduos dão inteligibilidade ao mundo que os cerca. Assim "como a prática pedagógica, como a ação docente, os media falam com alguém, exprimem uma ideia, um conteúdo, tem intenção de transmitir, divulgar conhecimentos" (Setton, 2015, p. 9). 
Entender os impactos das tradicionais formas de media e dos novos media digitais, bem como os processos de socialização e formação por eles incorporados e mobilizados e o papel pedagógico destes meios é de fundamental importância no momento em que os indivíduos estabelecem uma relação quase que ubíqua com as tecnologias da informação e comunicação, adicionando-as de modo quantitativo e qualitativo ao seu universo pessoal e social.

Pressupondo que toda ação educativa é uma ação sócio-interativa e comunicativa que exige envolvimento e relação, assim como toda prática mediática é um ato de mútua-ação, a aprendizagem em espaços formativos escolares e não escolares implica impreterivelmente na própria formação do sujeito tendo na informação e no conhecimento eixos centrais. Compreender a cultura mediática pode ser uma pista para compreender a cultura pedagógica e o contrário também pode ser verdadeiro. Educação e comunicação, nessa perspetiva, são fenômenos e componentes inseparáveis e complementares de um amplo e complexo processo: o da aprendizagem e da formação humana. Pensar os processos educativos implica estar atento ao seu viés comunicativo. Pensar os processos comunicativos fomentados pelos media exige atenção às suas implicações pedagógicas. Com o presente artigo, teórico e de caráter bibliográfico, pretendemos apontar alguns elementos que nos parecem essenciais para pensarmos a educação e os media convencionais e os novos medias digitais e suas múltiplas e complexas relações.

\section{OS MEDIA E SUA FACETA PEDAGÓGICA}

Partimos do pressuposto de que a prática de transmitir (produzir, selecionar, elaborar e distribuir) conhecimentos ou valores em forma de mensagens a que os media se propõem é uma ação pedagógica, ou seja, enquanto comunicam sentidos e valores exercem uma atividade educativa. Tanto os media quanto as práticas pedagógicas institucionalizadas (escolares) fundamentam suas práticas a partir do intercâmbio de informações, saberes, valores e sentidos.

Assim, a escola, que deixou de ser o único lugar de legitimação do saber pelo fato de que existe uma multiplicidade de saberes que circulam e outros espaços, difusos e descentralizados, e os media configuram-se como mediadores de sentidos, oferecendo, no campo da cultura, discursos que criam, consolidam ou difundem visões de mundo e que expressam ideias, posicionamentos e modos de pensar bem como 


\section{Reflexões em um Campo de Fronteiras: Educação e Comunicação em Diálogo}

comportamentos que são considerados aceitáveis ou reprováveis dentro de um contexto histórico-social. Da difusão descentralizada de saberes, possibilitada por um "ecossistema comunicativo", emerge novas configurações culturais e novas formas de ver, de ler, de aprender e conhecer o mundo. Para Martín-Barbero (2000), um dos principais intelectuais da América Latina e referência na pesquisa da comunicação e educação, a diversificação e difusão do saber, fora da escola é um dos desafios mais fortes que o mundo da comunicação e, especialmente dos novos media digitais apresenta aos sistemas educacionais. Segundo o autor, “o saber é disperso e fragmentado e pode circular fora dos lugares sagrados nos quais antes estava circunscrito e longe das figuras sociais que antes o administravam" (Martín-Barbero, 2000, p. 55). Isso significa dizer que vivemos uma época em que as tecnologias da informação e da comunicação estão em toda a parte. É impossível não admitir a presença dos produtos e dos discursos/enunciados mediáticos em nossa forma de viver e pensar e na constituição pluriforme do sujeito, exposto e que vive sob a égide destas tecnologias.

Desta maneira a análise da cultura mediática e a compreensão da sua presença na configuração dos modos de pensar dos indivíduos e sua intervenção no processo de significação da realidade que o cerca, deve necessariamente levar em conta as condições sócio-políticas e históricas de produção e consumo das mensagens nos contextos específicos de produção da cultura. "É preciso investigar o contexto da produção, é necessário observar as condições de difusão e receção das mensagens, bem como o sentido/significado que assumem em determinadas circunstâncias" (Setton, 2015, p. 18). Pensar os modos de produção e apropriação das mensagens mediáticas pressupõe igualmente discutir e analisar como ocorrem os processos educativos de uma maneira geral, o que implica pensar e repensar como se dão os processos pedagógicos que se realizam mediados pelos media ou pela escola. Ambos, podem ser vistos como espaços onde são produzidos sentidos, ambientes de mediação de sentidos entre produtores, consumidores de informações e conhecimentos sob a forma de mensagens. Que tendências pedagógicos ou que "lógicas" pedagógicas estão presentes ou podem ser pensados a partir de experiências mediáticas tendo em vista os processos culturais e histórico-sociais em que tais experiências estão inseridas? Em que medida o campo da Comunicação configura-se em espaço para experiências educativas e formativas?

Em função das novas tecnologias, especialmente dos novos media digitais, as interações sociais não dependem mais de um local físico, no sentido de que a constituição do eu incorpora, também numerosos acontecimentos e experiências que extrapolam os limites geográficos. O advento dos meios de comunicação social reflete a forma 
como as novas relações sociais modificam inclusive as noções de tempo e espaço, deixando-se guiar pela ideia de interação separada das particularidades e vicissitudes do lugar em que ocorrem. Nos familiarizados com eventos, com ações, e com a aparência visível de cenários físicos a milhares de quilômetros de onde vivemos. "O advento da mídia eletrônica, sem dúvida, acentuou este aspecto de deslocamento, na medida em que enfatiza a presença tão instantaneamente e a tanta distância" (Giddens, 1991, p. 155).

Os media tendem a contribuir para a criação uma aldeia global, onde todos os indivíduos assistem aos acontecimentos importantes se desdobrarem e assim participam em maior ou menor intensidade, com maior ou menor grau de reflexividade sobre eles. Neste mundo interconectado as pessoas vivenciam os mesmos acontecimentos a partir de muitos locais diferentes. Giddens (2012) destaca-se como um teórico social que, ao refletir sobre os sentidos da sociedade analisa a relação entre a modernidade e os aspectos mais pessoais da existência humana. No texto Sociologia, de caráter eminentemente didático, o autor apresenta/faz um resgate histórico e analisa, dentre vários temas, a recente revolução das tecnologias da comunicação e como estas tem impactado nas sociedades ao redor do mundo, bem como seus efeitos nos processos de socialização e individualização por ela fomentados. Como indivíduos não controlamos a mudança tecnológica, e alguns críticos "perceberam que o ritmo acelerado dessas mudanças ameaçam inundar as nossas vidas. [...] Entender o impacto das novas formas de media digital será uma tarefa importante para as próximas gerações" (Giddens, 2012, p. 550).

No referido texto, Giddens aponta que os entusiastas destas tecnologias acreditam que elas têm a potencialidade de promover novas formas de relacionamento que viriam a complementar ou melhorar as interações presenciais existentes, o que traria uma adição positiva para a constituição do indivíduo e crucial para qualquer sociedade. De outra parte, muitos não têm uma perspetiva tão entusiástica, e temem que a difusão cada vez maior das novas tecnologias venha a aumentar o isolamento social e a atomização da sociedade. O contato humano seria reduzido e as relações sociais deixadas de lado, o que enfraqueceria o tecido da vida social. Outros, no entanto reconhecem o papel altamente positivo dos novos mass media, mas afirmam que ao mesmo tempo não podemos simplesmente querer que seu lado obscuro desapareça.

No início do século XX, teóricos da que ficou conhecida como corrente funcionalista (Harold Lasweell, Max Webber, dentre outros) se concentraram em compreender como os media poderiam ajudar a integrar e unir as sociedades de maneira a 


\section{Reflexões em um Campo de Fronteiras: Educação e Comunicação em Diálogo}

estabilizar o sistema social. Para estes os media possibilitavam um fluxo contínuo de informações e questões que podem afetar os indivíduos pessoalmente. Além disso, eles contribuiriam no sentido de fazer o indivíduo entender as informações que eles trazem, bem como na tarefa de reconhecer novos acontecimentos e forjar valores comuns, além de terem a capacidade de mobilizar os indivíduos para que contribuam com o equilíbrio e o funcionamento social. No entanto, “as explicações funcionalistas têm pouco ou nada a dizer sobre a receção dos produtos dos media pelo público, tendendo a pressupor que os indivíduos sejam recetores relativamente passivos em vez de intérpretes ativos das mensagens dos media" (Giddens, 2012, p. 530).

Na esteira oposta, numa perspetiva crítica, de inspiração marxista, a chamada teoria do conflito analisa como os mass media representam, na prática e no discurso, interesses econômicos de uma determinada classe social, que, por meio deles, disseminam seus modos de ser e de pensar ao restante da população. Nesta perspetiva as tecnologias da comunicação eram vistas como um instrumento ou uma ferramenta a serviço de um processo de dominação de uma classe sobre a outra, de um indivíduo sobre o outro. Neste ponto de vista, constituiriam-se em aparelhos ideológicos que, nas mãos de grupos dominantes, teriam o objetivo de distorcer a realidade a fim de não permitir ao indivíduo uma perspetiva informada e consciente sobre suas vidas e sobre o mundo ao seu redor, legitimando e justificando os interesses destes grupos na ordem social. Os teóricos da Escola de Frankfurt ${ }^{1}$ sustentavam que a disseminação da indústria cultural, ou seja, a produção em grande escala de produtos culturais padronizados e dominada pelo desejo de lucrar tanto quanto em outro setor, voltados para o maior púbico possível, enfraquece a capacidade individual de pensamento crítico e independente. Neste sentido, o que inicialmente poderia representar um espaço público de diálogos acaba por levar a termo uma representação muito específica de self, de modo que as características individuais não seriam mais consideradas, mas abduzidas pelas características da massa. As críticas a esta perspetiva residem no fato de que ela supõe que as pessoas não conseguem resistir aos apelos dos media tornando-se presas deles e de que as críticas se concentram na produção da cultura dando pouca ou nada atenção ao público e à complexidade do processo de receção das mensagens.

1 A Escola de Frankfurt consistia em um grupo de intelectuais que, a partir da década de 1920, produzia um pensamento conhecido como Teoria Crítica. Dedicaram-se ao estudo dos problemas tradicionais do movimento operário, unindo trabalho empírico e análise teórica. Os autores ligados à Escola de Frankfurt não se pretendiam ser comentadores ou intérpretes do pensamento de Marx, mas tinham como proposta buscar inspiração no marxismo para uma análise da sociedade contemporânea. 
De um ponto de vista bem menos negativo e hostil aos media, os estudos interacionistas percebem que cada vez mais os meios de comunicação de massa modernos, em vez de negar a possibilidade de pensamento crítico, de fato poderiam proporcionar muitas formas de informação e espaços qualificados de debates, mas que, no entanto, ainda pecam por tratar as pessoas como agentes passivos, apenas recetores das suas mensagens, ignorando as capacidades dos indivíduos de processar e manipular de formas diferentes as informações e os discursos.

As mensagens dos media costumam ser discutidas por indivíduos durante e após a receção. [Elas] são transformadas por meio de um processo contínuo de contar e recontar, interpretar e reinterpretar, comentar, rir e criticar. [...] Recebendo as mensagens e incorporando-as às nossas vidas [...] estamos constantemente moldando e remoldando nossas habilidades e estoque de conhecimento, testando nossos sentimentos e gostos, e expandindo os horizontes da nossa experiência. (Thompson, 1995, p. 42-43)

A pergunta que vem à tona é: de fato, os meios de comunicação de massa proporcionam para os indivíduos uma ampliação dos diálogos sobre as questões cruciais de nossa época alargando os espaços públicos para o engajamento dos sujeitos nos debates políticos, morais ou de qualquer espécie?

Outros autores se destacam neste cenário, como, por exemplo o francês Jean Baudrillard (1991), que considera que os media de massa modernos não somente nos relatam o que está acontecendo com o mundo e consequentemente conosco para nós, mas cada vez mais definem aquilo que o mundo é na realidade. $\mathrm{O}$ autor aponta para o fato de que o limite sempre tênue entre realidade e representação entrou em colapso, e de que a representação se torna mais real do que o próprio real (hiper-realidade). Segundo ele assistimos a cobertura dos media sobre os acontecimentos para sabermos o que realmente está acontecendo. Vivemos em uma época em que as tecnologias da informação e da comunicação estão em toda a parte e da mistura do comportamento das pessoas e das imagens dos media forma-se uma nova realidade.

Para Gidens (2002, p. 32), "nas condições da modernidade, os meios de comunicação não espelham realidades, mas em parte as formam. O que não deve nos levar à conclusão de que os meios de comunicação criam um reino autônomo de 'hiper-realidade, onde o signo ou a imagem é tudo". 


\section{Reflexões em um Campo de Fronteiras: Educação e Comunicação em Diálogo}

As mais recentes teorias da receção apresentam formas diferenciadas de compreender o fenômeno dos media e seu impacto sobre os processos de socialização e individualização. Para os críticos do modelo hipodérmico os indivíduos exercem um papel qualitativamente mais ativo em relação às tecnologias da comunicação, reagem e interpretam os textos de diferentes maneiras levando sob o crivo de suas experiências de vida, condições socioculturais, interesses e necessidades. O modelo hipodérmico comparava a mensagem dos media como uma droga injetada com uma seringa. Baseava-se na ideia de que a audiência (como o paciente) recebe e aceita a mensagem de forma passiva e direta e não se envolve com ela de maneira crítica respondendo de maneira mais ou menos homogénia. Os media teriam o poder de, "drogando" a audiência, destruir sua capacidade reflexiva e de pensar criticamente. No entanto, atenta Giddens (2012, p. 540), atualmente "podemos ver um afastamento de modelos unidirecionais (dos media para a audiência), em favor de modelos bidirecionais que permitem espaço para os expectadores influenciarem a produção dos media”, em vez de simplesmente serem esponjas passivas que absorvem tudo o que surge pela frente.

É impossível, deste modo, não reconhecer as imensas transformações nos modos de ser e de estar no mundo dos sujeitos decorrentes da presença e do desenvolvimento dos meios de comunicação. Esta presença ostensiva traz consigo muitas possibilidades, "até contraditórias entre si, inclusive a de sufocar as pessoas pelo excesso de alcance de informações, assim como de libertá-las da desinformação e do isolamento" (Nascimento, 2009, p. 144).

Do mesmo modo não se pode pressupor que os diversos formatos dos media sejam politicamente neutros ou antecipadamente afirmar que sejam socialmente maléficos ou benéficos. Ou depositar neles a esperança de que tenham absoluto sucesso no seu intento de propiciar informações que reconheçam e explorem a complexidade das experiências humanas.

O que se conhece é que, se no século XXI, o mercado global dos media é controlado por não mais do que duas dezenas de megacorporações multinacionais. Estas, no mínimo, enquanto àqueles que constroem as notícias, elaboram as narrativas e dão inteligibilidade ao mundo, acabam por atuar como os "guardiões" para o que entra na agenda dos debates públicos. As chamadas "supercompanhia de media" concentram boa parte daquilo que é produzido, distribuído e comercializado de notícias, cultura e entretenimento, o que pode ser sentido em quase todos os países.

Quando falamos em imperialismo mediático, Tomlinson (Tomlinson, s.d., citado por Giddens, 2012, p. 544), em tom provocativo, pergunta: 
Será que ocorre quando pessoas de outras culturas assistem, e talvez passem a aceitar como superiores, produtos culturais ocidentais que são imbuídos de valores culturais ocidentais? Ou estará o imperialismo mediático na exportação de tecnologias específicas que perturbam culturas locais e as transformam? Ou será que ele existe quando as indústrias mediáticas de um país se tornam tão poderosas que controlam ou acabam com a mídia local? E será que podemos falar de dominação quando as pessoas ao redor do mundo decidem comprar aparelhos de TV e telefones celulares e na verdade dizem ver utilidade e prazer neles?

À medida que as corporações mediáticas se tornam ainda mais concentradas, centralizadas e globais em seu alcance, haverá razões para a preocupação de que o importante papel dos media como fóruns para o discurso, a expressão e o debate seja restringido. Isto pode representar um atentado ao pluralismo de ideias, à participação dos sujeitos na constituição do ambiente e do discurso público tão imprescindível às sociedades democráticas e capaz de apontar para as diferentes possibilidades de escolha do indivíduo livre.

Historicamente, há uma concentração dos Meios de Comunicação Social de Massa nas mãos de grupos privados de media que, comandadas de forma vertical reproduzem e amplificam ideias, concepções, valores para um universo gigantesco de pessoas. Como expressa Guareschi $(2005$, p. 80), “[...] a constatação a que se chega é que a voz da maioria dos cidadãos é silenciada, pois não tem a oportunidade de poder interferir democraticamente no projeto de construção de sua cidade". Os media ditos hegemônicos tendem a encarar, geralmente, os indivíduos não como participantes de um diálogo, mas sim, como espectadores. Para os indivíduos de uma determinada comunidade cabe tão somente espectar, isto é: assistir, observar determinado conteúdo cabendo-lhe tão somente a escolha entre receber as informações deste ou daquele veículo de informação.

A impressão que se tem é que, ao conceberem os indivíduos como meros espectadores, os Meios de Comunicação Social de Massa, nesta perspectiva, contribuem para a instauração de um processo de silenciamento da voz da maioria dos cidadãos. As possibilidades de participação dos sujeitos nos processos de significação do mundo se reduzem a partir da imposição de limites às experiências democráticas e emancipatórias, cerceando a possibilidade de exercerem amplamente "a sua capacidade de escolha e de formar suas próprias opiniões de tal modo que se possa aprofundar a vivência democrática" (Nascimento, 2009, p. 145). 


\section{Reflexões em um Campo de Fronteiras: Educação e Comunicação em Diálogo}

Desta maneira urge compreender de que modo atuam os Meios de Comunicação Social de Massa hegemônicos a partir de uma cultura homogeneizante tendo em vista que, invariavelmente, tendem a difundir um discurso padronizado e único obedecendo, em certa medida, uma orientação advinda da sociedade de massa e da cultura do consumo. Mesmo admitindo a crescente fragmentação em se tratando de apropriação, observando a quem se destinam, a que lógica obedecem e os condicionantes de produção dos Meios de Comunicação de Massa é possível perceber um oligopólio dos meios e um monopólio do discurso.

Tal diagnóstico indica que o imperialismo midiático tem potência para obstruir os espaços de diálogo público, contribuindo, de certa maneira, para a que as escolhas de estilos de vida sejam alienadas, irreflexivas, consolidando biografias não coerentes e nunca ou nem ao menos minimamente revisadas. Os media, nestas condições, ofertar-nos-ia uma pseudo-esfera pública, criando um ambiente de meras relações públicas em vez de ser geradora de um genuíno debate público.

Em qualquer esforço de análise dos media não se pode furtar da necessidade de levar em conta a concentração econômica dos meios e a sua organização no que se refere às relações de poder ideológico, político e cultural. É preciso considerar as condições de produção visto que boa parte da receção está de alguma forma condicionada, tocada, orientada pela produção tanto em termos econômicos, mas ainda em termos narrativos ou semióticos.

Por outro lado, significativos estudos de audiência e de receção (Martin-Barbero, Marshall McLuhan), bem como os esforços empreendidos nesta seara pelos Estudos Culturais (Edward Thompson) apontam para o fato de que os consumidores são espectadores mais ativos do que se imaginava, podendo rejeitar, modificar e reinterpretar os produtos mediáticos. Tal perspetiva sugere que as mensagens dos meios são polissêmicas e a audiência é sempre ativa. Portanto o que é veiculado pelos media não é algo absoluto ou permanente para sempre nos recetores, mas eles apenas são orquestradores ou dão algum tom nas disputas ou discussões aparentemente como um cenário possível dentre os demais. Tal contradição é evidenciada pelos estudos de receção que, claramente, mostram o espaço cultural existente entre aquilo que se diz e aquilo que quem ouve se apropria ou à maneira como em situações específicas interpreta. "Assim como o professor, os media (quem os controla ou quem se serve deles), não sabem como sua intenção, suas ideias, desejos e projetos se realizarão" (Setton, 2015, p. 9). Ao comunicarem algo, mesmo que manifestamente (ou não) estejam presentes nas mensagens selecionadas os interesses ou os objetivos a que elas 
se propõem, mesmo calculadas estrategicamente a partir de organizados expediente que procuram prever como ou em que intensidade ou mesmo o que estas poderiam mobilizar no recetor, jamais saberão ou se controlará como elas foram compreendidas, apropriadas e interiorizadas pelos indivíduos.

Nesse horizonte, "não há modos de predizer que aspecto do termo será captado pelo espectador. Mesmo as mensagens mais poderosas [...] têm que se defrontar com a 'palavra' de resposta do espectador e com o mundo da experiência" (Newcomb, 2010, p. 384). Assim sendo, nenhuma resposta pode ser prevista, visto que os sentidos dos discursos não são dados, são criados.

Se os media nos aproximam, neste cenário, eles não o fazem de maneira homogênea. Ainda fica guardado a possibilidade aberta do diálogo vivo que movimenta as engrenagens da democracia o que permitiria modos de vida autorreflexivos e uma sociabilidade como construção social e coletiva. Os consumidores dos media "não são 'tolos culturais' que possam ser facilmente manipulados por interesses corporativos. À medida que o alcance e o volume das formas e conteúdos dos media se expandem, os indivíduos estão se tornando mais hábeis em interpretar e avaliar as mensagens e o material que encontram" (Giddens, 2012, p. 547).

Os indivíduos passam nesta concepção a não serem mais vistos como apêndices das grandes estruturas, e, na mesma medida, suas experiências não se dão apartadas destes contextos. Dessa forma "o projeto reflexivo do eu incorpora numerosos acontecimentos contextuais e formas de experiência através dos media, através dos quais deve estabelecer uma rota" (Giddens, 2002, p. 186).

Na esteira das sociedades contemporâneas e em meio às suas facetas multimodais, encontramo-nos todos expostos, para além da escola, em uma abertura comunicacional em que os media, devido ao seu indubitável impacto e sua difusão por todo o mundo, configuram-se como partícipes nos processos de constituição dos sujeitos e elementos de cultura. Não são raros os casos em que as crianças, por exemplo, permanecem mais tempo em relação direta com os media do que na escola ${ }^{2}$, e, de

2 O tempo médio por dia que crianças e adolescentes passam em frente à televisão no Brasil, por exemplo, chegou a 5h35, mais tempo que uma criança passa por dia na escola que é cerca de 3h15. Os dados coletados em 2015 fazem parte do Painel Nacional de Televisão, do Ibope Media, que registra a evolução do tempo dedicado à TV (canais abertos e fechados, não inclui os programas assistidos sob demanda) por crianças e adolescentes entre 4 e 17 anos de todas as classes sociais. Fonte: http://www.ebc.com.br/infantil/ para-pais/2015/06/tempo-de-criancas-e-adolescentes-assistindo-tv-aumenta-em-10-anos. Acesso em: 25 ago. 2017. Outras pesquisas revelam que a exposição aos meios, incluindo a media impressa, cobre a terceira parte do tempo dos seres humanos nas sociedades industrializadas, perdendo apenas para "dormir" e "trabalhar" (Baccega, 1999, p. 182). 


\section{Reflexões em um Campo de Fronteiras: Educação e Comunicação em Diálogo}

fato, os indivíduos se constituem cada vez mais e de forma intensa em consumidores e produtores mediáticos. Em especial, as novas gerações têm seus valores, opiniões e atitudes sedimentadas por veículos que acabam, não raras vezes, por impactar na constituição da consciência dos sujeitos mais profundamente que a educação desenvolvida na escola.

Nessa perspetiva, não se pode negar a omnipresença e a importância que os media (desde as mais tradicionais, como por exemplo, o rádio, a TV ou os jornais impressos, como os novos media digitais, capitaneadas pela rede mundial de computadores, a internet) têm alcançado em nossa vida individual e coletiva. De fato, como já preconizava, ainda em 1982, a Declaração de Grünwald3: "Vivemos num mundo onde os media são omnipresentes: um número cada vez maior de pessoas consagra grande parte do seu tempo a ver televisão, a ler jornais e revistas, a tocar discos e ouvir rádio". Não se pode ignorar que a paisagem mediática nas últimas décadas tenha apresentado transformações extraordinárias com a introdução dos novos media digitais. Alterações que têm trazido impactos profundos no campo da educação, da cultura, da política, da economia e de maneira geral, no cotidiano de todas as pessoas. Num cenário

[...] marcado pela multiplicidade de suportes, de formatos, de conteúdos, de mensagens, marcado pela conexão media-tecnologia, marcado pela pluralidade de discursos, pela vertigem da atualidade, pela voragem da mudança e da descoberta de novos acontecimentos, os media organizam e estruturam a nossa ligação ao mundo. (Lopes, 2011, p. 20)

Pode-se supor que, em meio a um mundo cada vez mais complexo e dinâmico, onde o conhecimento e a informação constituem-se elementos de poder e pressuposto básico para promoção da cidadania, ampliam-se as formas de construção do conhecimento, extrapolando os espaços e tempos formalizados historicamente. "O

3 Declaração assumida por educadores, comunicadores e investigadores oriundos de dezenove países e participantes no Simpósio Internacional sobre Educação para os Media ocorrido em Grünwald, na Alemanha, de 18 a 22 de janeiro de 1982, a convite da UNESCO. Disponível em: http://www.literaciamediatica.pt. A Declaração destaca a importância dos media e a obrigação dos sistemas educacionais de ajudarem os cidadãos a melhor compreenderem estes fenômenos. "Ressaltando a necessidade de mobilização e engajamento de todos os envolvidos com a socialização de crianças e jovens, ou seja, famílias, professores, comunicadores e responsáveis políticos e econômicos (decisores), no sentido de promover a construção de uma consciência crítica mais aguda de ouvintes, espectadores e leitores, a Declaração recomenda a integração entre sistemas de educação e comunicação" (Bévort \& Belloni, 2009, p. 1088). 
professor deixa de ser a 'fonte única' de informação passando a conviver (ou competir) com fontes alternativas, como os meios de comunicação (rádio, TV, revistas, jornais), razoável quantidade de livros didáticos nas escolas, internet, etc." (Caimi, 2003, p. 136). A aprendizagem assentada na mobilidade vem cada vez mais acontecendo em diferentes espaços pedagógicos. Estes espaços de produção e construção do conhecimento merecem atenção e devem ser mais bem explorados e pesquisados.

Não temos nenhuma pretensão de estabelecer linhas demarcatórias entre educação e comunicação, entre um e outro campo (o que não significa que elas se diluam num mesmo arcabouço teórico), mas de assinalar que suas aproximações podem ser frutíferas quando consideramos o fenômeno que estudam e não os objetos que constroem. Neste sentido, é mister ressaltar que ambas tomam como fenômeno de partida a existência de processos de relação entre sujeitos, de interação verbal que se presentificam no discurso e se materializam nas palavras. Assinalamos a centralidade dos media na vida das pessoas como lugares de produção e circulação de saberes, participantes e influenciadores, juntamente com a escola e outros agentes de socialização, nos processos de constituição da consciência do sujeito.

Entendemos que, de modo aproximado ao que ocorre no âmbito das práticas pedagógicas escolares (obviamente resguardando as especificidades de cada espaço), os media se dirigem a alguém, exprimem uma ideia, um conteúdo, têm intenção de transmitir, divulgar conhecimentos, mas, além disso, configuram-se como espaços onde significados e sentidos são negociados, narrativas são produzidas e vozes se constituem e entram em ação. Os media e a escola podem ser encaradas como espaços de produção de sentidos, circulação e geração de discursos, territórios compartilhados, universo de conflitos e lugares de aprendizagens.

Os processos comunicativos e mediáticos não se fundam na mensagem, mas nos modos de interação que os próprios meios possibilitam aos envolvidos no processo de comunicação discursiva, o que implica em processos educativos e formativos, visto o envolvimento dos sujeitos no processo de produção de enunciados e sentidos de mundo e, por consequência, na constituição de si próprios. A relevância pedagógica dos media reside na circulação de discursos onde a produção e receção configuram-se como espaços de criação e possibilidade de significação e ressignificação, mediados pela produção e pela cultura mediática.

Assim como a escola, os media igualmente ensinam, ainda que, por vezes, não de forma deliberada, intencional ou sistemática. Compreendemos que ensino não se reduz à transferência de conhecimentos, de saberes ou de uma cultura, nem, tampouco, 
caracteriza-se como ato de depositar informes ou comunicados às massas ou a extensão de conhecimentos técnicos. Educação pressupõe comunicação, "um encontro de sujeitos interlocutores que buscam a significação dos significados" (Freire, 1977, p. 69). A prática de produzir e transmitir (selecionar, elaborar, narrar e distribuir) conhecimentos ou significados em forma de mensagens a que os media se propõem, constituem-se num processo pedagógico. Sujeitos por meio delas se comunicam e negociam sentidos e valores e o fazem em um diálogo num jogo em que a palavra enunciada adquire sentidos para os que estão mobilizados no processo. A realidade inteligível é atravessada pela escola e pelos media.

\section{OS DESAFIOS (ESPECÍFICOS) DOS NOVOS MEDIAS DIGITAIS}

Os novos medias digitais hoje desafiam os sistemas educativos convencionais tendo em vista o fato de que fazem nascer novos modos de estar juntos, de outras sociabilidades e outras sensibilidades. Vimos nascer, especialmente, no século XXI um ambiente de informação e comunicação que mistura diversas formas de aprender e uma infinidade de saberes fortemente descentralizados e que extrapolam os sistemas educativos convencionais organizados em torno da escola e do livro. Do mesmo modo, e com tamanha intensidade, como afirma Martín-Barbero (2006), os novos media digitais, amparados pela rede mundial de computadores, transformam a relação do sujeito com o espaço e com o tempo. Se trata, segundo o autor, de um movimento de "desterritorialização e relocalização" (Martín-Barbero, 2006, p. 57).

O esquema, segundo Martín-Barbero (1997), no qual tudo "transcorria entre emissor-dominante e recetor-dominado, sem o menor indício de sedução nem resistência, e na qual, pela estrutura da mensagem, não atravessavam os conflitos nem as contradições e muito menos as lutas" (Martín-Barbero, 1997, p. 15), é insuficiente para compreender como se dão os processos comunicativos nos novos meios digitais e o que deles resulta. "O modo como as pessoas produzem o sentido de suas vidas e como se comunicam e usam os meios, não cabe no esquema” (Martín-Barbero, 1997, p. 16).

Para Martino (2014, p. 75),

[...] a circulação de informações encontra nas redes o melhor tipo de arquitetura. A velocidade da circulação de informações significa também que novidades 
estão presentes o tempo todo, gerando como padrão uma instabilidade constante, Qualquer informação pode ser alterada, completada ou cancelada por uma nova, muitas vezes se deixar indícios dos caminhos seguidos.

Segundo o autor, os novos media digitais permitiram inúmeras alterações nos modos e nas formas de relacionamento humano, ampliaram os espaços de interação e criaram fluxos de dados em rede, potencializaram a qualquer sujeito se tornar um produtor de conteúdo, redefiniram os conceitos de público/privado e reconfiguraram os espaços criando um mundo virtual e um ciberespaço ${ }^{4}$.

Este cenário nos provoca a pensar a comunicação como uma região onde se articulam diversidades, complexidades e pluralidade, sem que sejam deixados de lado as contradições, as relações de poder, os conflitos concretos e as batalhas travadas no campo do econômico e no terreno do simbólico. Martín-Barbero (1997, p. 292) afirma que é preciso abandonar o "mediacentrismo" e compreender os fenômenos mediáticos como parte de outros sistemas de maior envergadura, como o econômico, o político ou o cultural. Por isso, ao invés de falar apenas de meios, de novos meios digitais de comunicação, ou de apenas enfatizar que as mudanças tecnológicas trouxeram alterações instrumentais na comunicação, urge entender que a apropriação, uso, e produção de sentidos nestes espaços passa pela compreensão de que tal processo ocorre mediado pelo contexto cultural em que ocorre. Podemos pensar os processos de comunicação a partir da cultura e dos processos formativos que engendram, o que significa deixar de pensá-los a partir das disciplinas e dos meios. "Significa romper com a segurança proporcionada pela redução da problemática da comunicação à das tecnologias” (Martín-Barbero, 1997, p. 285). Significa que a comunicação se tornou questão de mediações mais do que de meios, uma questão de cultura e não apenas de meios e mensagens. Falar de comunicação é muito mais do que falar de meios (ou dos meios, sejam eles convencionais ou digitais), "pues hablar de comunicación es hablar de actores de prácticas sociales, procesos sociales y políticos”' (Martín-Barbero, 2008, p. 33).

Newcomb (2010, p. 381), em Sobre os aspectos dialógicos da comunicação de mas$s a$, contribui com a discussão afirmando que "numa perspetiva dialógica de comu-

4 Cada pessoa com acesso à internet faz parte do ciberespaço quando troca informações, compartilha dados, publica alguma informação. Já o mundo virtual existe enquanto possibilidade (não se opõe ao que seria um mundo "real") e que se torna visível quando acessado e permite não apenas a duplicação do mundo físico, mas também sua transformação.

5 "Porque falar em comunicação é falar de atores de práticas sociais, processos sociais e políticos" (Tradução nossa). 


\section{Reflexões em um Campo de Fronteiras: Educação e Comunicação em Diálogo}

nicação, o espectador é ativo, aceitando, rejeitando ou modificando aquilo que lhe é oferecido". O autor aponta para o fato de que é para a participação dos sujeitos envolvidos (a emissão e a receção) neste processo de construção de sentido, tendo em vista suas condições sociais de enunciação e de receção que devemos nos voltar, a fim de depurar nossas noções do papel da comunicação de massa no diálogo social e na constituição da consciência e do próprio sujeito.

Desse modo, o fenômeno dos novos media digitais deve ser visto como um fenômeno da comunicação, ou seja, um tipo de relação social que implica uma interlocução constante entre emissor e recetor, direta ou indiretamente. Mesmo considerando necessariamente os condicionantes estabelecidos pelos grupos economicamente dominantes, principais grupos produtores das mensagens mediáticas, e que invariavelmente direcionam os fluxos de conteúdos nos novos media digitais, é preciso considerar, por outro lado, que os ambientes digitais constituem-se como lugares de criação e produção de sentidos e configuram-se como espaços de significação e ressignificação ou possibilidades de transformação dos significados atravessados pela cultura.

A relevância pedagógica dos media digitais nos parece residir na circulação de discursos onde a produção e receção configuram-se como espaços de criação e possibilidade de significação, ressignificação e transformação de significados oferecidos pela produção e pela cultura mediática. Neste cenário de interação verbal e produção de sentido, constituído a partir de lutas e ou aceitação, resistência ou transformação dos significados das mensagens, desencadeia-se um processo interpretativo, atravessado pelos media e pelas novas tecnologias.

Gómes (2006) afirma que diversas são as incertezas trazidas pela introdução dos media digitais no campo de educação. "O quarto em que se usa o computador e/ ou se vê televisão se torna o cenário de várias vivências e experiências. [...] O que se aprende aí resulta muitas vezes mais relevantes do que aquele que se aprende em instituições educativas formais" (Gómes, 2006, p. 96). Isso significa dizer que, com a proliferação de oferta mediática e cibernética os processos educativos saem dos lugares certos, horários fixos e turnos determinados e reconfigura-se em destempos educativos, possíveis pelas mais recentes tecnologias da comunicação e informação.

Outra faceta das mudanças trazidas pelos novos media digitais apontada pelo autor diz respeito às fontes legitimadoras dos processos de aprendizagem. "Antes, o livro que o professor trabalhava na sala de aula tinha a 'última palavra'. [...] Desde as interacções mediáticas, os sujeitos-educandos questionam o professor, questionam 
seus saberes diante da abundância representacional e policromática dos ecossistemas comunicativos" (Gómes, 2006, p. 96).

Se não bastassem estas incertezas a elas se agregam outras, como por exemplo, o fato de que o paradigma informacional representado pelos novos media provoca reações nas figuras da razão e autoridades tradicionais, "desde o saber-acervo estabelecido e custodiado em bibliotecas e instituições até o saber-memória do professor com seus dotes enciclopédios" (Gómes, 2006, p. 97). Incertezas que desencadeiam temores nestes últimos que veêm a possibilidade de que suas atividades sejam substituídas por tecnologias de informação e nas instituições educativas convencionais que, em grande medida, insistem, teimosamente, em perceber apenas o aspeto instrumental dos novos media digitais e acabam por não compreender a magnitude das mudanças.

Estes desafios se alargam quando pensamos no sujeito frente aos novos media digitais. Quando tratamos acerca da formação do sujeito nos referimos aos processos educativos que resultam na constituição de sua consciência e na composição de uma singularidade que lhe é própria. A consciência se materializa na interação, no encontro entre sujeitos em uma situação de comunicação concreta (ou em situações concretas) que, em certa medida, justificam as posições dos sujeitos e que lhes permitem a elaboração de enunciados em uma situação discursiva. A consciência só se efetiva a partir do estabelecimento de uma relação entre falantes e é através da linguagem que o sujeito se torna consciente e começa a agir sobre o mundo, com e contra os outros. São os discursos que colocam os sujeitos em relação, os quais adentram numa corrente de comunicação verbal e, somente quando mergulham nessa corrente é que a consciência desperta e começa a operar.

Sob estas lentes recorremos ao que Wolton (2012) aponta como sendo um diagnóstico desta época em que os indivíduos estabelecem uma relação umbilical com as novas tecnologias digitais. $\mathrm{O}$ autor aponta quatro elementos que podem nos ajudar a compreender este cenário, a saber, (1) as solidões interativas, (2) a vivência do tempo, (3) a impossível transparência e (4) as distâncias intransponíveis.

$\mathrm{O}$ autor afirma que com o advento da internet entramos na era das "das solidões interativas" (Wolton, 2012, p. 100). Para ele, os sujeitos podem ser exímios internautas e terem, ao mesmo tempo, colossais dificuldades de manterem relações com as pessoas mais próximas com quem convivem diariamente. Múltiplas conexões não necessariamente garantem melhor comunicação. Mesmo com todas as competências que se tem diante das tecnologias não há garantias de qualificação das relações humanas. "Milhares de indivíduos saem assim, celular à mão, correio eletrônico conectado 


\section{Reflexões em um Campo de Fronteiras: Educação e Comunicação em Diálogo}

[...] como se tudo fosse urgente e importante, como se fosse morrer caso não pudesse ser encontrado a qualquer instante" (Wolton, 2012, p. 101).

Os computadores e outras tecnologias (tablets, smartphones), cada vez mais presentes na vida dos indivíduos, reduzem os deslocamentos e acentuam a rapidez dos atos de comunicação, comprimindo-os e até, em determinada medida, quase anulando-os. O esmagamento da duração da comunicação, do tempo para se falar, faz com que os indivíduos façam experiências que não tenham nenhuma relação com aquele de espaço-tempo da experiência humana, que exigem a vivência do tempo. Wolton alerta para o fato de que "há uma defasagem entre a rapidez dos sistemas de informação e a lentidão da comunicação humana que se almeja encontrar em uma maior presença das máquinas o meio de introduzir um pouco mais de racionalidade nas relações humanas" (Wolton, 2012, p. 102).

Em seguida, o autor destaca a impossibilidade de se estabelecer uma relação transparente entre os sujeitos na era dos novos media digitais. As relações, ao mesmo tempo em que se simplificam, tornam-se obscuras, blindadas, bloqueadas por artifícios, códigos, burocracias. "Cada um, apesar dos discursos que preconizam relações mais diretas, introduz, entretanto, intermediações burocráticas, filtros, regras, proibições, signos de distinção, para proteger sua relação com o outro" (Wolton, 2012, p. 103).

Por fim, o autor afirma que a hipótese de que as novas tecnologias de comunicação poderiam anular a defasagem entre emissor, recetor e mensagem parecer ser falsa. Os "ruídos" inerentes a toda situação de comunicação não são eliminados pela introdução de sistemas tecnológicos nos processos comunicativos. Para o autor, algumas "distâncias são intransponíveis" (Wolton, 2012, p. 104). Isso porque este é o espaço em que os sentidos são instituídos, é o espaço do embate. Reconhecer a atmosfera de tensões inerente à palavra, cujos sentidos só podem ser compreendidos considerando os espaços em que os sujeitos se movimentam e as posições que assumem em instituições de que participam, permite pensar o sujeito discursivo não como unitário e fixo, mas em constante devir e em diálogo constitutivo com o outro. Os sentidos não são dados de antemão, cristalizados pela estrutura sócio-política, mas ao se confrontarem com o mundo das experiências concretas, situadas, contingentes e históricas, permeadas pela hegemonia e resistência, são constantemente transformados, reapreciados, ressignificados, distorcidos, amplificados, desordenados em um campo cultural que se transforma constantemente.

Em resumo, segundo o autor, três são os desafios específicos dos novos media digitais e que não se resumem a eles. 
1. "As técnicas não bastam para criar comunicação" (Wolton, 2012, p. 131). Mesmo que a transmissão de informações esteja cada vez mais rápida ainda se fala em problemas de comunicação e incomunicabilidade. Os sujeitos não se contentam apenas com informações. O que está implicado nestas mudanças cada vez mais velozes é toda uma questão de relacionamento com o outro;

2. "É necessário iniciar rapidamente uma reflexão sobre o tipo de informação produzida por esses sistemas técnicos" (Wolton, 2012, p. 133). Além disso, o problema não está no acesso à informação, mas na capacidade de saber o que procurar e nos meios cognitivos que dispõe os indivíduos para contextualizar e compreender as informações disponíveis e delas se servir.

3. "É preciso atingir uma certa contextualização das novas tecnologias [...] e que a comunicação nunca é um direito adquirido, que ela é sempre fruto de uma batalha política" (Wolton, 2012, p. 137). Os novos media devem ser considerados dentro da história da comunicação e, dessa forma, inscritos no tempo da história das tecnologias e no espaço das sociedades para que se possa compreender sua performance, lógicas, os interesses econômicos e políticos envolvidos em suas ações e posições. Quem produz? Que mensagens e discursos são produzidos? Com qual intencionalidade? Quem controla os que produzem as mensagens veiculadas pelos novos media digitais? A quem se destinam e em que lógicas trabalham? Que tipo de resistências se constroem nestes ambientes? É preciso considerar tais condições de produção sob as quais estão engendrados os discursos mediáticos, visto que boa parte da receção está de alguma forma condicionada, tocada, orientada pela produção tanto em termos econômicos, políticos, mas ainda mais em termos narrativos ou semânticos.

\section{OS MEDIA COMO ESPAÇOS DE PRODUÇÃO DE SENTIDO E A PROMOÇÃO DO DIÁLOGO FORMATIVO}

Encaramos, enfim, os processos mediáticos como processos complexos, vivos, permanentemente inconclusos, cultural e socialmente constituídos, ambivalentes, constituídos por uma rica trama de vozes que não se fundem em uma única consciência, mas que fazem parte de um campo de forças e disputas no qual vozes são justapostas e contrapostas de modo a gerar algo para além delas mesmas.

Pensar os modos de produção e apropriação das mensagens mediáticas pressupõe igualmente analisar como ocorrem os processos educativos de uma maneira geral, o 


\section{Reflexões em um Campo de Fronteiras: Educação e Comunicação em Diálogo}

que implica discutir como se dão os processos pedagógicos que encontram nos media ou na escola ambientes onde são produzidos sentidos, enquanto espaços de mediação entre produtores, consumidores de informações e conhecimentos sob a forma de mensagens e que dão inteligibilidade a si mesmos e ao mundo que os rodeia.

Ao tratar destas novas experiências nos campos da educação e da comunicação, haja vista a emergência de modos compartilhados de produção de saberes atravessados por recursos tecnológicos e mediáticos, e por um universo social cada vez mais complexo e multifacetado, é possível identificar diferentes tipos de abordagens e de ancoragens que se podem construir a partir das questões que emergem do encontro entre estes dois campos do saber e da pesquisa.

Não é de hoje que o debate sobre as interfaces entre media e educação se apresenta. As interlocuções vão desde a perspetiva da promoção da leitura crítica dos meios e das mensagens mediáticas, passando pela dimensão do uso das tecnologias da comunicação e informação como ferramentas pedagógicas, até as experiências mediáticas dos sujeitos em ambientes intra e extra-escolar. Peruzzo (1999, p. 205) destaca que os estudos que enfatizam as relações e inter-relações entre educação e comunicação o fazem a partir de alguns posicionamentos específicos: 1) a questão do ensino-aprendizagem enquanto mediado por um processo comunicativo; 2) a utilização de meios de comunicação na educação presencial, nas instituições de ensino; 3 ) o papel dos media no processo de educação; 4) a educação para a receção crítica das mensagens transmitidas através dos meios massivos, especialmente a televisão. Para Girardi e Jacobus (2009, p. 34),

[...] comunicação e a educação estão intimamente ligadas. A comunicação é a forma de expressar o que se quer dizer, com um determinado conhecimento, para alguém que quer compreender a mensagem a ser dita. Já a educação, por meio de um processo de formação, torna o indivíduo apto a organizar as idéias e, a partir daí, comunicar-se de forma eficiente. Nós só vamos nos comunicar bem se organizarmos nossas ideias de forma clara e direta, com um aprendizado que nos dê conhecimento sobre o que queremos expressar, utilizando uma linguagem adequada.

As diversas abordagens possíveis apontam a preocupação teórico-prática no âmbito da pesquisa acadêmica com a temática e demonstram a atualidade desta questão, num momento histórico em que as tecnologias da comunicação e informação com- 
põem, juntamente com as instituições convencionais de ensino, espaços de produção, negociação e circulação de saberes socialmente construídos e mediaticamente distribuídos e que impactam sensivelmente na constituição do sujeito e no seu ambiente social. Não indicamos os modos de perceber as interfaces entre estes dois campos com a intenção de problematizá-los de modo apurado, ou esgotarmo-nos no assunto, nem sugerindo que apenas esses vieses dão conta da amplitude do tema. Mas para reforçar a tese da existência de uma íntima relação entre educação e comunicação e mostrar as possíveis formas de encarar a questão, a fim de nos familiarizarmos ainda mais com esse espaço de fronteiras abertas, territórios complexos e multifacetados, constituídos pelo entrecruzamento de sentidos, saberes, sujeitos e instituições.

O fenômeno dos media de massa, então, deve ser apontado como um fenômeno comunicativo, ou seja, um tipo de relação social que implica um diálogo constante entre emissor e recetor. A produção, difusão e receção fazem parte de um complexo processo de criação numa cultura mediaticamente mediada.

Entre o alarmismo e a dissimulação, a massificação e o relativismo, Giddens (2012) aponta o "diálogo vivo" como alternativa para tal impasse. Sugere que, não só os media, mas os processos educativos (formais e não formais), devem se converter em ambientes favoráveis para o diálogo de caráter formativo.

O diálogo, como jogo político, que abre espaço para a experimentação pessoal e coletiva dos rumos adotados pelos indivíduos e permite, sem a autoridade absoluta da tradição, a adoção de uma postura mais gerativa, um engajamento político positivo, o que Giddens chama de "política-vida”. Nesta perspetiva ele afirma que há uma nova identidade para o eu na modernidade, passível de monitoramento e revisão.

$\mathrm{O}$ eu torna-se um projeto reflexivo, baseando-se em identidade auto-construída, individual e coletivamente. [...] A exiguidade de dilemas - situação típica tanto em sociedades tradicionais, que forneciam 'guias' inquestionáveis para as ações, quanto da arrogância racionalista de alguns momentos da modernidade, nos quais o progresso era tido como inexorável - na modernidade tardia perde espaço para uma atmosfera problematizadora, questionadora, que a cada momento coloca desafios a reflexividade do sujeito (Oliveira \& Zangelmi, 2012, p. 119-120).

O que nos parece ser o fato primordial a ser discutido é que os media, tanto quanto as práticas pedagógicas institucionalizadas, escolares, à sua maneira, podem ser 
compreendidas à luz das interações que em torno deles se constitui e da produção de sentidos que nelas e através delas ocorrem. Para além da capacidade de selecionar ou agendar o que devemos discutir e conhecer do cotidiano, é também pela mediação da escola e dos media que o mundo que conhecemos é narrado, traduzido e compreendido. Ou seja, estes espaços concorrem com o indivíduo na significabilidade do mundo. Não são apenas meios de informação ou transmissores de significados, mas constituem-se em espaços de interação onde sentidos são produzidos, construídos e reconstruídos, e onde sujeitos se encontram a fim de travar uma disputa pela interpretação do mundo e de si próprios.

Desta forma, em face a vários cenários possíveis, sejam eles nos espaços escolares ou mediáticos, a reflexividade, a formação humana pode se configurar no diálogo radical, aberto, livre e consciente, desvencilhada de ordenamentos institucionais ou socialmente pré-fixados ou engessados no tempo e no espaço. O diálogo vivo possibilita a constituição de uma individualidade permanentemente revisitada, infindavelmente revisada, e criticamente refletida, o que fortalece a autenticidade do eu e de seu projeto reflexivo.

\section{REFERÊNCIAS}

Baccega, M. A. (1999). Comunicação \& Educação: do mundo editado à construção do mundo. Comunicação \& Informação, 2 (2), 176- 187.

Baudrillard, J. (1991). Simulacros e simulações. Lisboa: Relógio D’Água editores.

Bévort, E., \& Belloni, M. L. (2009). Mídia-Educação: conceitos, história e perspectivas. Educação e sociedade, 30 (109), 1081-1102.

Caimi, F. E. (2003). A crise da escola e o 'mal-estar' docente. História: debates e tendências, 4 (1), 133-141.

Freire, P. (1977). Extensão ou comunicação? Rio de Janeiro: Paz e Terra.

Giddens, A. (1991). As consequências da modernidade. São Paulo: Editora UNESP.

Giddens, A. (2002). Modernidade e identidade. Rio de Janeiro: Zahar.

Giddens, A. (2012). Sociologia. Porto Alegre: Penso. 
Guareschi, P. (2005). Mídia e democracia. Porto Alegre: P.G/OB.

Girardi, I., \& Jacobus, R. (2009). Para fazer rádio comunitária com “C” maiúsculo. Porto Alegre: Revolução de Ideias.

Gómez, G. O. (2006). Comunicação social e mudança tecnológica: um cenário de múltiplos desordenamentos. In D. Moraes (Org). Sociedade Midiatizada (pp-8198). Rio de Janeiro: Mauad.

Lopes, P. C. (2011). Educação para os media nas sociedades multimidiáticas. CIES e-Working Paper, $\mathrm{n}^{\circ}$ 108/2011. Publicação do CIES do Instituto Universitário de Lisboa.

Martín-Barbero, J. (1997). Dos meios às mediações: comunicação, cultura e hegemonia. Rio de Janeiro: Editora da UFRJ.

Martín-Barbero, J. (2000). Desafios Culturais: da comunicação à educação. Comunicação \& Educação, 18, 51-61. Acedido em http://www.revistas.usp.br/comueduc/article/view/36920/39642

Martín-Barbero, J. (2006). Tecnicidades, identidades, alteridades: mudanças e opacidades da comunicação no novo século. In D. Moraes (Org). Sociedade Midiati$z a d a$ (pp. 51-80). Rio de Janeiro: Mauad.

Martino, L. M. S. (2014). Teoria das mídias digitais: linguagens, ambientes e redes. Petrópolis: Vozes.

Nascimento, A. (2009). Educação e comunicação: diálogos contemporâneos e novos espaços de reflexão. In A. D. Nascimento \& T. M. Hetkowski (Eds.), Educação e contemporaneidade: pesquisas científicas e tecnológicas (pp. 133-158). Salvador: EDUFBA.

Newcomb, H. (2010). Sobre aspectos dialógicos da comunicação de massa. In A. P. Ribeiro, \& I. Sacramento (Orgs). Mikhail Bakhtin: linguagem, cultura e mídia (pp. 49-87). São Carlos: Pedro \& João Editores.

Oliveira, F. R., \& Zangelmi, A. J. (2012). Modernidade e Reflexividade: Anthony Giddens e a interpretação do mundo contemporâneo. Isegoria, Ano 1, vol 1, n2, 111-123. 
Reflexões em um Campo de Fronteiras: Educação e Comunicação em Diálogo

Peruzzo, C. M. K. (1999). Comunicação comunitária e educação para a cidadania. Comunicação \& Informação, 2 (2), 205-228.

Setton, M. G. (2015). Mídia e educação. São Paulo: Contexto.

Thompson, J. (1995). Ideologia e cultura moderna: Teoria social e crítica na era dos meios de comunicação de massa. Petrópolis: Vozes.

Wolton, D. (2012). Internet, e depois? Uma teoria crítica das novas mídias. Porto Alegre: Sulinas. 